\title{
Intact Verbal and Nonverbal Short-term Memory Following Damage to the Human Hippocampus
}

\author{
Carolyn Backer Cave* and Larry R. Squire \\ Veterans Affairs Medical Center and Department of Psychiatry, \\ University of California, San Diego
}

\begin{abstract}
Short-term memory was assessed in two groups of amnesic patients. Six patients had confirmed or suspected damage to the hippocampal formation, and six patients had diencephalic damage as a result of alcoholic Korsakoff's syndrome. Verbal short-term memory was evaluated with seven separate administrations of the standard digit span test in order to obtain a precise measure of short-term memory. Nonverbal short-term memory was evaluated with four tests that assessed apprehension, retention, and the ability to manipulate nonverbal material-all within the span of immediate memory. One of these four tests assessed short-term memory for spatial location. Patients with damage to the hippocampal formation had a digit span equivalent to that of control subjects and also performed normally on the four tests of nonverbal short-term memory. The patients with Korsakoff's syndrome had a marginally low digit span and performed poorly on three of the four nonverbal tasks, a finding consistent with the deficits in attention and visuospatial processing previously described for this patient group. These deficits are likely due to the frontal lobe atrophy typically associated with Korsakoff's syndrome, rather than to diencephalic damage. The results support the view that short-term (immediate) memory, including short-term spatial memory, is independent of the hippocampus.
\end{abstract}

Key words: amnesia, short-term memory, diencephalon, hippocampus, spatial

Bilateral damage to the hippocampus and related structures or damage to the medial diencephalon causes severe memory impairment (Damasio, 1984; Squire, 1987; Markowitsch, 1988; Victor et al., 1989; Butters and Stuss, 1990; Squire and Zola-Morgan, 1991). The hallmark of the impairment is anterograde amnesia, i.e., a failure to establish long-term memory for new facts and events, regardless of the sensory modality in which information is presented. By contrast, immediate (short-term) memory has been considered to be intact in amnesia (Talland, 1965; Drachman and Arbit, 1966; Baddeley and Warrington, 1970). For example, it has been noted that even severely amnesic patients can retain small amounts of material in memory for a few seconds, sometimes up to a minute or more if they are not distracted (Milner, 1966). This dissociation between impaired long-term memory and apparently intact short-term memory has been fundamental to understanding the normal function of the structures damaged in amnesia. Moreover, it has provided some of the best evidence for the distinction between short-term and longterm memory first emphasized by James (1890) and devel-

* Currently at the Department of Psychology, Vanderbilt University, Nashville, Tennessee.

Correspondence and reprint requests to: Larry R. Squire, Veterans Affairs Medical Center, V-116A, 3350 La Jolla Village Drive, San Diego, CA 92161 oped during this century within experimental psychology (Waugh and Norman, 1965; Glanzer and Cunitz, 1966; Atkinson and Shiffrin, 1968; Wickelgren, 1975).

Despite its theoretical importance, the assessment of shortterm memory in amnesia has depended on a limited number of measures. The most frequently employed assessment of immediate memory capacity is the digit span test. This test requires that subjects repeat increasingly longer series of digits immediately after hearing them until the number of digits presented exceeds the ability to report them correctly. Amnesic patients are considered to perform normally on this test (Penfield and Milner, 1958; Drachman and Arbit, 1966; Baddeley and Warrington, 1970). However, the estimate of digit span for an individual subject is typically based on a single assessment of the maximum number of digits that can be correctly repeated, and it is usually presented as a whole number, i.e., an integer (see Baddeley and Warrington, 1970, for a variant of the standard digit span test in which each subject was assessed several times at each string length). Accordingly, the digit span test as usually administered provides a relatively insensitive test of the idea that short-term memory is intact in amnesia. For example, in one early study, control subjects had an average digit span that was more than one digit longer than the span of amnesic patients (Drachman and Arbit, 1966). Although this difference was not statistically significant, it is also unlikely that the standard digit span test 
could detect a one-digit loss in digit span, at least with the numbers of subjects usually evaluated. A more sensitive estimate of digit span could be obtained if the estimate were based on multiple assessments of each subject and if the digit span for each subject could be calculated to one decimal place.

A second issue is that digit span evaluates only one aspect of short-term memory. Short-term memory is not a single entity (e.g., Baddeley, 1981; Monsell, 1984) but a collection of separate capacities intrinsic to information-processing systems. For example, short-term memory for verbal (or verbalizable) material can be distinguished from short-term memory for nonverbal material.

Spatial short-term memory is of special interest in the context of human amnesia because of the proposal that the hippocampus has an important role in spatial memory ( $O$ 'Keefe and Nadel, 1978). According to this hypothesis, the hippocampus serves as a cognitive map, a memory system that stores information about allocentric (viewpoint-independent) space. This proposal about the hippocampus and spatial cognition suggests that the hippocampus is needed to carry out certain kinds of spatial (allocentric) computations and that hippocampal damage impairs the ability to perform such computations. The hippocampus could perform this function only in long-term memory, or it could be needed for the construction of cognitive maps even within immediate memory. The effect of hippocampal damage on spatial cognition has not been thoroughly explored within the span of immediate memory.

In one study, monkeys with bilateral lesions of the hippocampal formation could not acquire a spatial memory task, even though the interval between the sample and the choice was only 10 seconds (Parkinson et al., 1988). It is possible that for the monkey an interval of $\mathbf{1 0}$ seconds is outside the range of immediate memory, and that this task primarily assessed the ability to establish long-term memory for spatial information. However, the result does raise the possibility that hippocampal lesions impair a basic ability to carry out spatial computations and that this deficit is as apparent in immediate (short-term) memory as in long-term memory.

In one study with humans, four patients with presumed hippocampal damage and three patients with Korsakoff's syndrome were normal at remembering the location of a single dot on a sheet of paper after a 60-second delay (Warrington and Baddeley, 1974). In another study, the amnesic patient H.M. performed above chance across delays up to 16 seconds on a delayed matching to sample task involving ellipses. However, it was not determined at what delay his performance became abnormal or whether his performance was normal at the shortest delays (Sidman et al., 1968).

Amnesic patients with Korsakoff's syndrome, who have diencephalic damage together with frontal lobe atrophy, have been reported to retain nonverbal material for a few seconds as well as normal subjects (e.g., nonsense shapes or a sequence of locations to be touched) (Samuels et al., 1971; Warrington and Baddeley, 1974; Cermak et al., 1977; Haxby et al., 1983). Yet, these patients have also been reported to have visuospatial deficits that affect certain aspects of perception and encoding (Talland, 1965; Butters and Cermak, 1980). For example, patients with Korsakoff's syndrome have been found to be poor at identifying geometric figures embedded within more complex figures (Talland, 1965; Kapur and Butters, 1977) and at matching faces that differed in their superficial characteristics (Dricker et al., 1978). Such deficits would be expected to impair short-term memory for visuospatial material.

The purpose of the present study was to assess short-term memory functions for verbal and nonverbal material, including spatial short-term memory, in amnesic patients with confirmed hippocampal damage and in patients with Korsakoff's syndrome. Verbal short-term memory capacity was evaluated with multiple administrations of the conventional digit span task. In addition, four different tests were used to assess apprehension, retention, and the ability to manipulate nonverbal information-all within the span of immediate memory (Fig. 1). One of these four tested short-term memory of spatial information.

\section{EXPERIMENT 1}

Experiment 1 assessed the verbal short-term memory capacity of amnesic patients using the standard digit span task. The task was administered to each subject seven different times on seven different occasions in order to provide an improved measure of digit-span memory in amnesia and a rigorous test of the hypothesis that short-term verbal memory is intact.
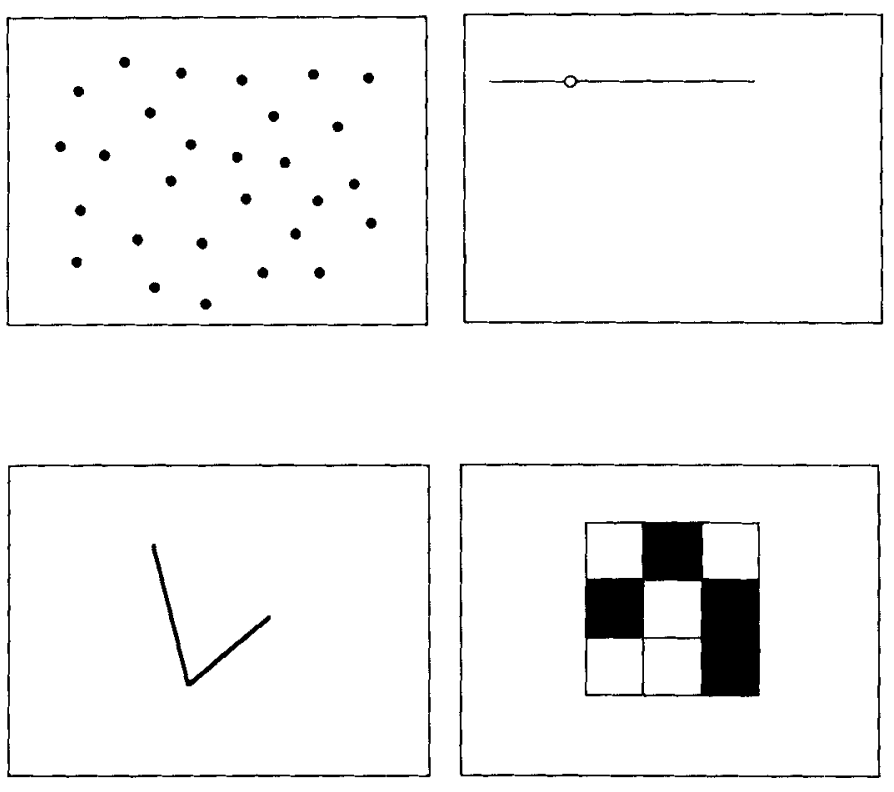

Fig. 1. Examples of the study stimuli used for experiments 2-5. In experiment 2 (upper left), dots were displayed for 200 $\mathrm{ms}$ and subjects estimated the number of dots displayed. In experiment 3 (upper right), a line and dot were displayed for 2 seconds. Subjects later attempted to recall the location of the dot on the line. In experiment 4 (lower left), an angle was displayed for 1 second. Subjects later judged whether a second angle was the same or different from the study stimulus. In experiment 5 (lower right), a $3 \times 3$ array of squares was displayed for 3 seconds. Subjects later judged whether a second array was or was not a correct mirror reversal of the study stimulus. 


\section{Methods}

\section{Subjects}

Twelve amnesic patients were tested (Table 1).

Patients with damage to the hippocampal formation. Six of the patients, all male, had confirmed or suspected damage to the hippocampal formation. Quantitative magnetic resonance imaging for four of these patients showed that the area of the hippocampal formation was $57 \%$ of normal size (Squire et al., 1990). In all four patients, the dentate gyrus, hippocampus, and subiculum were affected. All six of the patients have been described in detail previously (Cave and Squire, 1991). Quantitative information concerning each patient's memory impairment is presented in Tables 1 and 2 .

These patients averaged 63.8 years of age at the time of experiment 1. (Experiment 1 was conducted earlier than the other experiments; Table 1 shows the ages of the patients during experiments 2-5.) They averaged 15.8 years of education and had an average Wechsler Adult Intelligence ScaleRevised (WAIS-R) IQ of 110.7. Individual IQ and Wechsler Memory Scale-Revised (WMS-R) index scores appear in Table 1. Scores for other memory tests appear in Table 2. Note that the scores on the word recall test in Table 2 are above zero because on this test of immediate recall, several items can be retrieved from immediate memory. Immediate and delayed ( 12 minutes) recall of a short prose passage averaged 5.2 and 0 segments, respectively ( 21 segments total; Gilbert et al., 1968). The mean score on the Dementia Rating Scale (Mattis, 1976) was 132.2 (maximum possible, 144; range, 129-137). Most of the points lost on this test were from the memory subportion (mean, 8.0 points lost). The average score on the Boston Naming Test was 54.8 (maximum pos- sible, 60 ; range, 47-58). Scores for normal subjects on these same tests can be found elsewhere (Janowsky et al., 1989; Squire et al., 1990).

Patients with damage to the diencephalon (Korsakoff's syndrome). Six of the amnesic patients had alcoholic Korsakoff's syndrome (four men and two women). All of these patients have been described previously (Cave and Squire, 1991). Tables 1 and 2 present quantitative information about each patient's memory impairment.

The patients with Korsakoff's syndrome averaged 56.8 years of age at the time of experiment 1. (Table 1 shows the patient ages during experiments 2-5.) They averaged 11.3 years of education. Their average WAIS-R IQ was 99.5 . Individual IQ and WMS-R index scores appear in Table 1. Scores on other memory tests appear in Table 2 . Immediate and delayed (12 minute) recall for a short prose passage averaged 5.3 and 0 segments, respectively ( 21 segments total). The mean score on the Dementia Rating Scale (Mattis, 1976) was 129.2 (maximum possible, 144; range, 119-141), with an average of 7.0 points lost from the memory subportion of the test and 4.3 points lost from the initiation-perseveration subportion. The average score on the Boston Naming Test was 54.8 (maximum possible, 60; range, 48-57).

Healthy control subjects. Eight healthy subjects (two men and six women) were tested as controls for the patients with damage to the hippocampal formation. They were either volunteers or employees at the Veterans Affairs Medical Center, or recruited from the UCSD retirement community. They averaged 51.1 years of age (range, 42-59) and 15.7 years of education (range, 12-20) and their WAIS-R Information and Vocabulary subtest scores averaged 21.9 (23.5 for the pa-

Table 1. Characteristics of Amnesic Patients

\begin{tabular}{|c|c|c|c|c|c|c|c|}
\hline \multirow[b]{2}{*}{ Lesion Group } & \multirow{2}{*}{$\begin{array}{c}\text { Age } \\
\text { (years) }\end{array}$} & \multirow[b]{2}{*}{ WAIS-R IQ } & \multicolumn{5}{|c|}{ WMS-R } \\
\hline & & & Attention & Verbal & Visual & General & Delay \\
\hline \multicolumn{8}{|l|}{$\begin{array}{l}\text { Hippocampal } \\
\text { formation }\end{array}$} \\
\hline$A B^{*}$ & 52 & 104 & 87 & 62 & 72 & 54 & $<50$ \\
\hline $\mathrm{PH}$ & 68 & 115 & 117 & 67 & 83 & 70 & 57 \\
\hline WH & 67 & 113 & 88 & 72 & 82 & 67 & $<50$ \\
\hline WI & 76 & 99 & 92 & 72 & 82 & 71 & 58 \\
\hline JL & 70 & 116 & 122 & 73 & 83 & 74 & 58 \\
\hline LM & 59 & 117 & 124 & 94 & 82 & 89 & 62 \\
\hline Mean & 65.3 & 110.7 & 105.0 & 73.3 & 80.7 & 70.8 & 55.8 \\
\hline \multicolumn{8}{|l|}{ Korsakoff } \\
\hline $\mathrm{NC}$ & 46 & 90 & 62 & 80 & 60 & 69 & $<50$ \\
\hline $\mathrm{RC}$ & 73 & 106 & 115 & 76 & 97 & 80 & 72 \\
\hline VF & 70 & 103 & 101 & 78 & 72 & 72 & 66 \\
\hline $\mathrm{DM}$ & 55 & 101 & 92 & 55 & 64 & 50 & 51 \\
\hline PN & 62 & 99 & 81 & 77 & 73 & 67 & 53 \\
\hline JW & 53 & 98 & 104 & 65 & 70 & 57 & 57 \\
\hline Mean & 59.8 & 99.5 & 92.5 & 71.8 & 72.7 & 65.8 & 58.2 \\
\hline
\end{tabular}

WAIS-R, Wechsler Adult Intelligence Scale-Revised; WMS-R, Wechsler Memory Scale Revised.

The WAIS-R and each of the five indices of the WMS-R yield a mean score of 100 in the normal population with a standard deviation of 15. The WMS-R does not provide scores for subjects who score below 50 . Therefore, the three scores below 50 were scored as 50 for calculating group means.

* Although the lesion has not been confirmed radiologically, the etiology of the amnesia (anoxia) suggests that damage has occurred to the hippocampal formation. 
Table 2. Performance on Standard Memory Tests

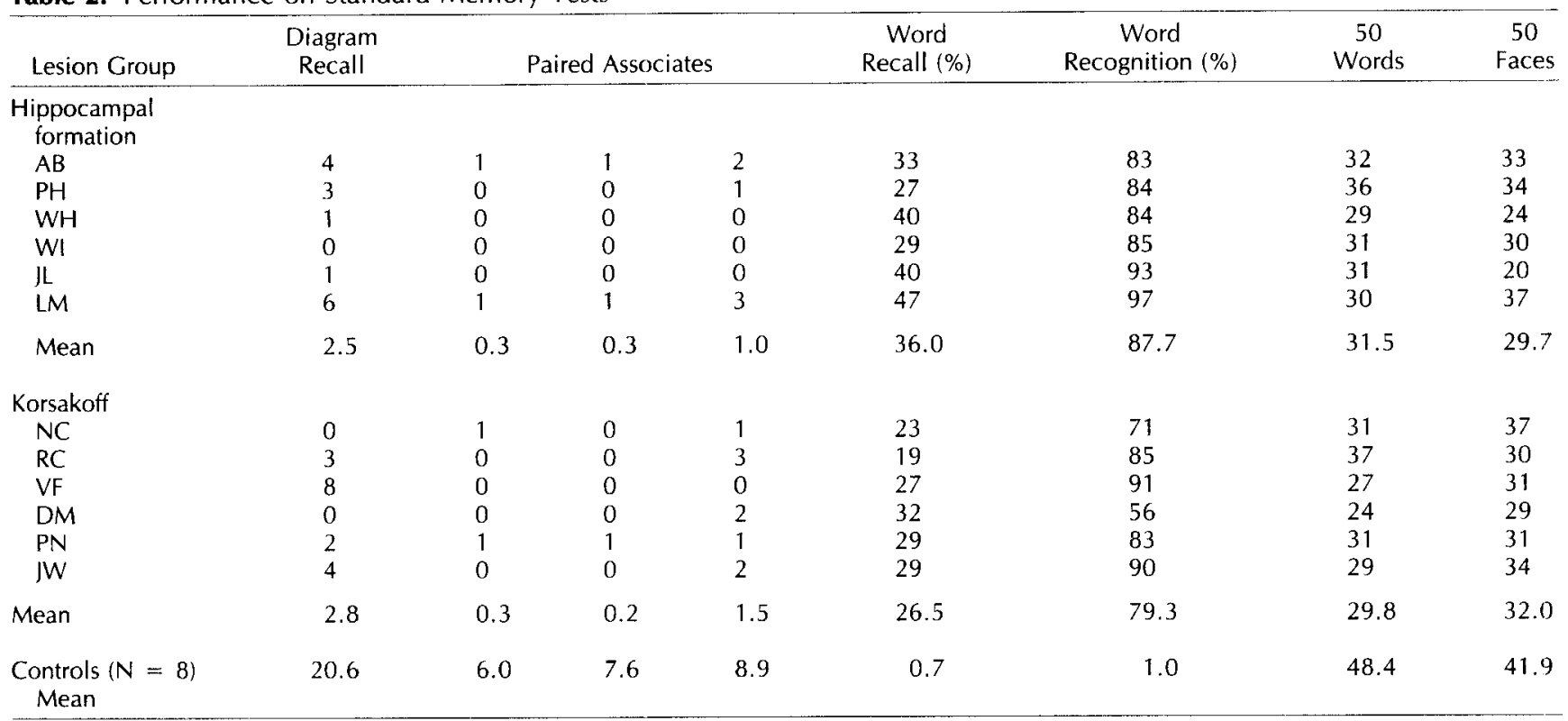

The diagram recall score is based on delayed (12 minutes) reproduction of the Rey-Osterrieth figure (Osterrieth, 1944; maximum score, 36). The average score for copying the figure was 27.5 , a normal score (Kritchevsky et al., 1988). The paired associate scores are the number of word pairs recalled on three successive trials (maximum score, 10/trial). The word recall score is the percentage of words identified correctly across five successive study-test trials (Rey, 1964). The word recognition score is the percentage of words identified correctly by yes/no recognition test across five successive study-test trials. The score for words and faces is based on a 24-hour recognition test of 50 words or 50 faces (modified from Warrington, 1984; maximum score, 50, chance, 25.) The mean scores for normal control subjects shown for these tests are from Squire and Shimamura (1986).

tients) and 57.0 ( 57.2 for the patients). Immediate and delayed (12 minutes) recall of a short prose passage averaged 8.2 and 7.2 segments, respectively.

Alcoholic control subjects. Eight alcoholic subjects (six men and two women) were tested to serve as a control group for the patients with Korsakoff's syndrome. All subjects were current or former participants in alcohol treatment programs in San Diego County. None reported a history of cirrhosis or severe head injury (specifically, a period of unconsciousness lasting longer than 5 minutes). The subjects reported an average drinking history of 16.4 years (range, 2-35 years) and had abstained from alcohol for an average of 40 months (range, 14-100 months) prior to participating in the study.

The alcoholic control subjects were matched to the patients with Korsakoff's syndrome for age (53.8 years; range, 4464), education (13.0 years; range, 12-16) and two WAIS-R subtest scores: vocabulary (alcoholic subjects, mean, 45.3; Korsakoff patients, mean, 53.5) and information (alcoholic subjects, mean, 19.4; Korsakoff patients, mean, 20.2). Immediate and delayed recall (12 minutes) of a short passage averaged 7.0 and 5.1 segments, respectively.

\section{Materials}

Subjects were tested on seven different digit span tests, taken from a pool of eight available tests. Each test was administered in a different session. The tests were identical to the forward digit span subtest of the WAIS-R. For each test, two strings of digits were available at each length from three digits to nine digits. The digits in each string were chosen randomly (without replacement) from the integers 1-9. The order of the administration of the seven tests was different for each subject. Test sessions were scheduled at least 1 day apart (mean, 20 days).

\section{Procedure}

The tests were administered exactly as in the WAIS-R. The task of the subject was to repeat a string of digits in correct order after the experimenter read the string. The test began with strings of three digits. For each trial, the digit string was read by the experimenter at a rate of approximately one digit per second without voice intonation to signal its length. When the string had been read, the subject immediately attempted to repeat the digits in the correct order. Two strings were given at each length. If at least one string of a particular length was repeated successfully, the test continued with two strings consisting of one additional digit. The test was discontinued when subjects failed both strings of a given length. For each test, the maximum number of digits correctly repeated (the digit span) was recorded, as well as the total number of strings correctly repeated.

\section{Results \\ Patients with damage to the hippocampal formation}

The amnesic patients performed virtually the same as the healthy control subjects (Fig. 2). The average span of the patients was 6.8 , averaged across the seven test sessions, and the average span of the control subjects was also 6.8 digits $(t[12]=0.08, P>.50)$. The patients and the control subjects both repeated an average of 8.6 strings correctly $(t[12]=$ $0.06, P>.50$ ). 


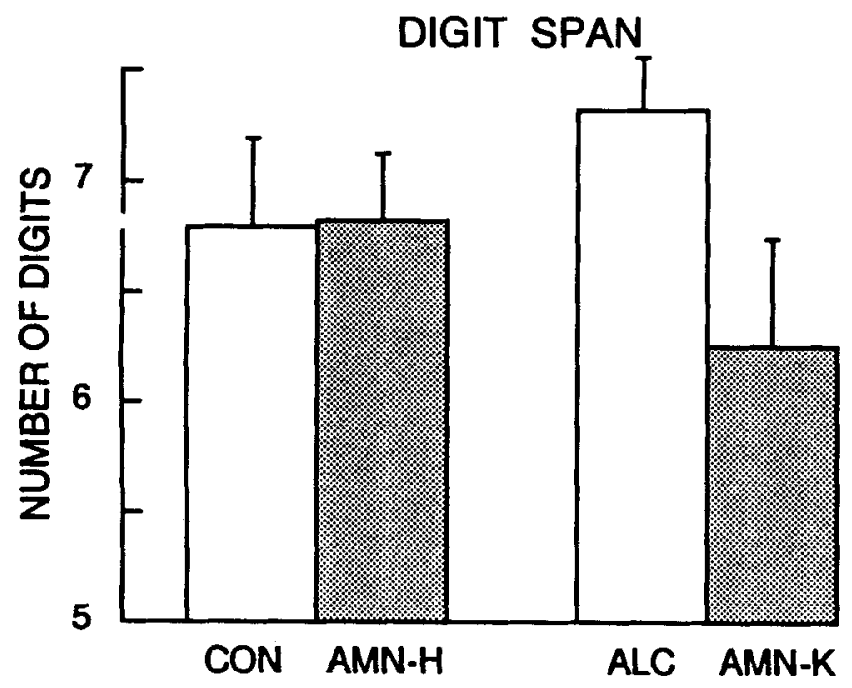

Fig. 2. Mean digit span derived from seven separate tests given to each subject. CON, healthy control subjects; AMN$\mathrm{H}$, patients with damage to the hippocampal formation; ALC, alcoholic control subjects; AMN-K, patients with Korsakoff's syndrome. Brackets show standard error of the mean.

\section{Patients with Korsakoff's syndrome}

These patients performed marginally more poorly than the alcoholic control subjects. The average span for the patients with Korsakoff's syndrome was 6.3 , and the average span of the alcoholic group was 7.3 digits $(t[12]=2.2, P<.06)$. It should be noted that the digit span of the alcoholic control group was numerically higher than that of the healthy control group, though not significantly so (Fig. 2). The digit span score of the patients with Korsakoff's syndrome was not significantly impaired in comparison to the healthy control subjects $(t[12]=0.84, P>.20)$, nor was it significantly impaired in comparison to all 16 control subjects $(t[20]=1.6, P>$ $.10)$.

The patients with Korsakoff's syndrome also completed fewer strings correctly in comparison with the alcoholic subjects (7.4 vs. 9.2), although this difference fell short of significance, $(t[12]=2.0, P<.07)$. Again, it should be noted that the patients with Korsakoff's syndrome did not differ from the healthy control subjects with respect to the number of digit strings completed $(t[12]=1.1, P>.20)$ and differed only marginally from the combined group of all 16 control subjects $(t[20]=1.7, P<.10)$.

The two patient groups did not differ from each other either in average digit span or in the number of strings correctly repeated (both $P>.20$ )

\section{Discussion}

The results of experiment 1 confirm the traditional view that memory-impaired patients with damage to the hippocampal formation have intact short-term memory, as measured by digit span. This conclusion can now be stated at a higher level of certainty than before, because the sensitivity of the present method was nearly an order of magnitude greater than in previous assessments of digit span memory in amnesic patients. The utility of the present method is shown by the fact that no subject exhibited the same digit span performance in every test session, i.e., no subject yielded the same whole number throughout testing. Accordingly, the estimate of digit span is more precise when digit span is calculated to one decimal place than when it is calculated as an integer.

Patients with Korsakoff's syndrome were marginally impaired in digit span, partly due to the fact that their control group performed somewhat better than expected. One reason for their marginally poor performance is that patients with alcoholic Korsakoff's syndrome typically have frontal lobe atrophy (Jacobson and Lishman, 1987; Shimamura et al., 1988), and damage to the frontal lobes can impair digit span performance (Janowsky et al., 1989). In support of this suggestion, two memory-impaired patients with confirmed diencephalic lesions, but without frontal lobe pathology (patients N.A. and M.G.; Squire et al., 1989; Cave and Squire, 1991), performed very well on this same digit span test (average span, 7.6 and 8.0 digits, respectively). This finding suggests that whatever difficulty the patients with Korsakoff's syndrome may have in digit span is unlikely to be due to their diencephalic lesions. In any case, digit span performance was fully intact in the patients with hippocampal damage. This finding sets the stage for additional tests of immediate memory, which assess the ability to apprehend, retain, and manipulate spatial information.

\section{EXPERIMENT 2}

Experiment 2 was designed to evaluate the ability of amnesic patients to apprehend and make a judgment about nonverbal material within the span of immediate memory. The task required subjects to estimate the number of dots flashed briefly on a computer screen.

\section{Methods}

\section{Subjects}

The amnesic patients were the same patients tested in experiment 1.

Healthy control subjects. Eleven healthy control subjects (eight men and three women) were tested as controls for the patients with damage to the hippocampal formation. One of these subjects had also participated in experiment 1. They were either volunteers or employees at the Veterans Affairs Medical Center, or they were recruited from the UCSD retirement community. They were selected to match the patients with respect to age (mean, 63.1; range, 56-74), education (mean, 14.4; range, 12-17), and two WAIS-R subtest scores, information (control subjects, mean, 22.5; patients, mean, 23.5) and vocabulary (control subjects, mean, 55.2; patients, mean, 57.2). Immediate and delayed (12 minutes) recall of a short prose passage averaged 6.0 and 5.0 segments, respectively.

Alcoholic control subjects. Eight alcoholic subjects (six men and two women) were tested to serve as a control group for the patients with Korsakoff's syndrome. Three of these subjects had also participated in experiment 1 . All subjects were current or former participants in alcohol treatment programs in San Diego County. None reported a history of cirrhosis or 
severe head injury (specifically, a period of unconsciousness lasting longer than 5 minutes). The subjects reported an average drinking history of 27.1 years (range, 14-48 years) and had abstained from alcohol for an average of 51.8 months (range, 4 months to 16 years) prior to participating in the study. The alcoholic control subjects were matched to the patients with respect to age ( 57.3 years; range, 46-68), education (12.6 years; range, 11-15), and two WAIS-R subtest scores, vocabulary (alcoholic subjects, mean, 51.0; Korsakoff patients, mean, 53.5) and information (alcoholic subjects, mean, 18.9; Korsakoff patients, mean, 20.2). Immediate and delayed recall (12 minutes) of a short prose passage averaged 6.8 and 5.6 segments, respectively.

\section{Materials}

The stimuli consisted of groups of black dots (approximately $2 \mathrm{~mm}$ in diameter) displayed on a computer screen on a white background (Macintosh SE or plus; screen size approximately $17.6 \mathrm{~cm}$ wide $\times 11.6 \mathrm{~cm}$ high). The displays consisted of 3-104 dots. The dots were arranged randomly on the screen with the constraint that equal numbers of dots appeared in each screen quadrant. (For displays of numbers not divisible by 4 , the dots were distributed as equally as possible in each quadrant.) There were 28 different possible displays: displays of 3-12 dots; displays of 15, 18, 20, 24, 28, or 32 dots; and displays of 38-104 dots, in increments of 6 dots. For display sizes of 3-32 dots, four different trials of each display size were presented. For displays of 38-104 dots, one trial of each display size was presented. Altogether, 76 trials were presented. The order of trials was random with the constraint that equal numbers of display sizes occurred in each quarter of trials. Two different trial orders were prepared, and each was administered to half of the subjects.

\section{Procedure}

Subjects were instructed to respond to each dot display with an estimate of how many dots had been shown. It was explained that sometimes there would be very few dots and sometimes very many, and that the dots would be visible on the screen only briefly. Subjects were asked to make their best estimate if they were unsure how many dots had been shown. To begin, two practice displays (of 4 and 20 dots), respectively) were presented in order to familiarize subjects with the procedure. No feedback was given on these or any subsequent trials. Each test trial began with a fixation asterisk (for $50 \mathrm{~ms}$ ), followed by a $200 \mathrm{~ms}$ exposure of the dot display. The trials were paced by the experimenter with approximately 2 seconds between trials.

\section{Scoring}

Two measures of performance were calculated. First, we calculated the average percent error for each display size (the actual number of dots minus the estimated number of dots, divided by the actual number of dots, multiplied by 100). The direction of error (positive or negative) was retained in this measure. Second, we calculated the average numerical estimate for each display size. Estimates for display sizes greater than 32 were averaged into three groups such that four trials contributed to estimates for 38-56 dots, 62-80 dots, and 86-104 dots (mean, 47, 71, and 95 dots, respectively).

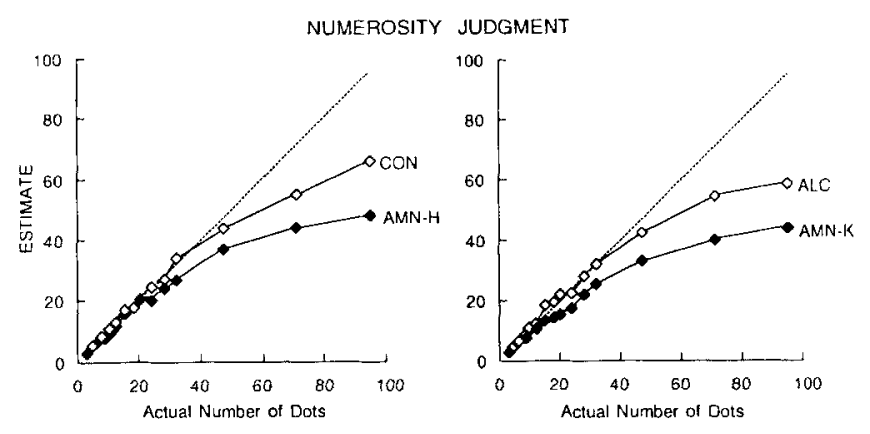

Fig. 3. Estimates of the number of dots displayed (for 200 $\mathrm{ms}$ ) in relation to the actual number displayed. Dashed line indicates perfect performance. CON, healthy control subjects; AMN-H, patients with damage to the hippocampal formation; ALC, alcoholic control subjects; AMN-K, patients with Korsakoff's syndrome.

\section{Results}

\section{Patients with damage to the hippocampal formation}

For all the displays of 3-104 dots, the control subjects and the patients performed similarly (Fig. 3, control subjects overestimated by an average of $3 \%$; patients underestimated by an average of $5 \% ; F[1,15]=1.1, P>.20$ ). Errors were positive (overestimates) for displays up to 20 dots and were negative (underestimates) for displays of greater than 20 dots $(F[18,270]=10.4, P<.001$, for the main effect of display size on percent error). There was no group by display size interaction $(F[18,270]=1.2, P>.20)$. An analysis based on the actual numerical estimates gave the same pattern of results. The average numerical estimate for the control group was 20.5 dots; for the patients, 17.3 dots. The actual average number of dots was 22.4 .

It has been shown previously (Kaufman et al., 1949; Ginsburg, 1978) that normal subjects underestimate large groups of randomly displayed dots. This phenomenon was observed in both subject groups. The actual average number of dots in the large displays (those with more than 32 dots) was 71 . For these displays, the control subjects and the patients made similar estimates of 54.9 and 41.7 , respectively $(P>.20)$. The average estimate made by the patients was significantly less than the actual number of dots $(t[5]=12.1, P .001)$; the average estimate made by the control subjects fell just short of significance $(t[10]=2.04, P<.07)$. There was considerable variability in the estimates for large numbers of dots, particularly among the control subjects, and a few control subjects overestimated the numbers of dots in the large displays.

\section{Patients with Korsakoff's syndrome}

Across all the displays of 3-104 dots, the performance of the alcoholic control subjects and the patients with Korsakoff's syndrome was marginally different (Fig. 3, alcoholic control subjects overestimated by an average of $2.9 \%$; patients underestimated by an average of $11.7 \% ; F[1,12]=$ $4.08, P<.07$ ). Errors were positive (overestimates) for displays up to 15 dots and were negative (underestimates) for displays of greater than 15 dots; $F[18,216]=17.7, P<.001$ 
for the main effect of display size on percent error). There was also a group by display size interaction $(F[18,216]=$ $2.7, P<.001)$. Patients with Korsakoff's syndrome began to underestimate in response to displays of greater than 8 dots, whereas the alcoholic subjects did not begin to underestimate consistently until the displays were greater than 32 dots. An analysis based on the actual numerical estimates gave a similar pattern of results, though none of the differences were significant. Thus, across all display sizes (actual mean number of dots, 22.4), the patients with Korsakoff's syndrome gave lower estimates than the alcoholic control subjects (15.9 vs. $20.1 ; P>.10)$. The group by display size interaction also failed to reach significance $(P>.10)$.

Both the control subjects and the patients showed the normal phenomenon of underestimating large displays of dots. The alcoholic control subjects and the patients made similar estimates of 52.0 and 39.2 , respectively $(P>.20)$. Both estimates were significantly less than the actual average number of dots (71 dots; both $P<.05$ ).

A separate comparison involving the two patient groups across the full range of display sizes indicated that they performed similarly $(F[1,10]=1.4, P>.20)$. The effect of display size was significant $(F[18,180]=28.7, P<.001)$, and there was no indication of group by display size. Analysis of the actual numerical estimates gave the same results.

\section{Discussion}

Patients with hippocampal damage were as good as normal subjects at estimating how many dots were presented. Thus, these patients apparently have no difficulty either apprehending or making judgments about numerosity. Both groups demonstrated the normal phenomenon of underestimating large numbers of randomly distributed dots. The patients underestimated large displays somewhat more than normal subjects, but not significantly so.

The results for the patients with Korsakoff's syndrome suggested that they may have a deficit in apprehending and judging numerosity. They tended to make larger estimation errors than their control subjects $(P<.07)$. They also underestimated displays of 9 or more dots, whereas their control subjects did not consistently underestimate until displays of 38 or more dots were presented. As with digit span, it is possible that this impairment is related to the attentional deficits associated with frontal lobe damage, rather than to memory impairment itself. Experiment 3 assesses the ability to store and retrieve single spatial locations.

\section{EXPERIMENT 3}

Experiment 3 was designed to evaluate the ability of subjects to remember the location of a dot on a horizontal line (Posner and Konick, 1966; Milner, 1974), both at short intervals after inspecting the dot (0-12 seconds) and at a longer delay ( 24 seconds).

\section{Methods}

\section{Subjects}

The same amnesic patients were tested as in experiment 2 , except that patient D.M. was not available for testing.

Healthy control subjects. See experiment 2.
Alcoholic control subjects. Seven of the eight alcoholic control subjects from experiment 2 were tested.

\section{Materials}

Subjects were asked to study the location of a dot on a horizontal line (Fig. 1) and then, after a variable interval, to demonstrate memory for its location by marking a different line at the precise spot that the dot had previously appeared. A $12-\mathrm{cm}$ horizontal line was first displayed in one quadrant on a Macintosh computer screen. A dot (a circle approximately $2.5 \mathrm{~mm}$ in diameter) appeared on the line at any of 16 equally spaced locations along the length of the line, excluding the center of the line and $2 \mathrm{~cm}$ at either end. At test, a $12-\mathrm{cm}$ horizontal line appeared in the diagonally opposite quadrant on the computer screen, but no dot was present. Subjects were asked to indicate on this line where the dot had been located. Two kinds of study-test trials were presented. Sixty trials were presented with an unfilled delay between study and test (12 trials at each of five delays: $0,1,2$, 6 , or 12 seconds), and 36 trials were presented with a distraction task filling the entire delay (12 trials at each of three delays: 6,12 , or 24 seconds). For each kind of trial (filled and unfilled) and for each delay (0-24 seconds), the dot appeared at study about equally often in the 16 possible locations.

All 60 unfilled trials were presented first, preceded by 6 practice trials. The five kinds of delay trials $(0,1,2,6$, or 12 seconds) were presented in a random order, with the constraint that no more than three trials of a particular delay occurred consecutively. Immediately after these 60 trials were presented, there were 6 more practice trials, followed by 24 additional trials with either 6 or 12 seconds of distraction during the delay. Twelve trials at each delay were presented in mixed fashion. Finally, in a separate session, given on a subsequent day, 12 trials were given with a 24 -second, distraction-filled delay. This test was preceded by four practice trials.

\section{Procedure}

Trials with unfilled delays. The subjects were told that their task was to remember the location of a dot on a line. Verbal instructions were accompanied by large index cards, illustrating different stages of a trial. Subjects pressed the computer keyboard spacebar to initiate each trial. A black horizontal line with a dot located on the line appeared on a white computer screen for 2 seconds of study. The screen was then blank (white) during the delay $(0,1,2,6$, or 12 seconds) while subjects waited quietly. After the delay, a blank line appeared together with a small plus sign. Using the computer mouse, the subject moved the plus sign along the line, attempting to place the vertical line of the plus sign precisely at the center of where the circle had been. If necessary, subjects were reminded of what they were supposed to do. The subject then pressed the button on the mouse, thereby recording the screen coordinates of the plus sign for later analysis.

Trials with distraction-filled delays. These trials were identical to the trials just described, except that subjects performed a distraction task during the delay interval. The distraction task consisted of naming aloud in ascending order one- and twodigit numbers that were displayed in random order on the 
screen. For delays of 6 or 12 seconds, 14 numbers between 0 and 50 appeared in two horizontal rows on the screen. For delays of 24 seconds, 21 numbers were displayed in three rows.

\section{Scoring}

For each trial, the error in locating the dot was calculated in millimeters as the absolute value of the remembered location subtracted from the actual location of the dot on the horizontal line. Because the line constrained responses in the vertical direction, the vertical axis was ignored in the error calculation.

\section{Results}

\section{Patients with damage to the hippocampal formation}

Performance was considered separately for trials with unfilled delays and distraction-filled delays (Fig. 4). The patients performed normally on trials with unfilled delays. The control subjects misplaced the dot by an average of $3.5 \mathrm{~mm}$, and the patients misplaced the dot by an average of $4.6 \mathrm{~mm}(F[1,15]$ $=1.6, P>.20)$. Performance declined marginally at the longer delays $(F[4,60]=2.2, P<.09)$.

The patients and the control subjects also performed similarly when the delays were filled by a distraction task. The average error made by the control subjects and the patients was $8.6 \mathrm{~mm}$ and $10.0 \mathrm{~mm}$, respectively $(F<1)$. For both groups, performance tended to be poorer at the longer delays $(F[2,30]=3.1, P<.06)$. There was a trend toward an interaction between subject group and delay, indicating that the patients with hippocampal damage did perform more poorly than the control subjects at the longest delay (controls, mean error at 24-second delay, $8.0 \mathrm{~mm}$; patients, mean error at 24second delay, $12.3 \mathrm{~mm} ; F[2,30]=3.0, P<.07)$.

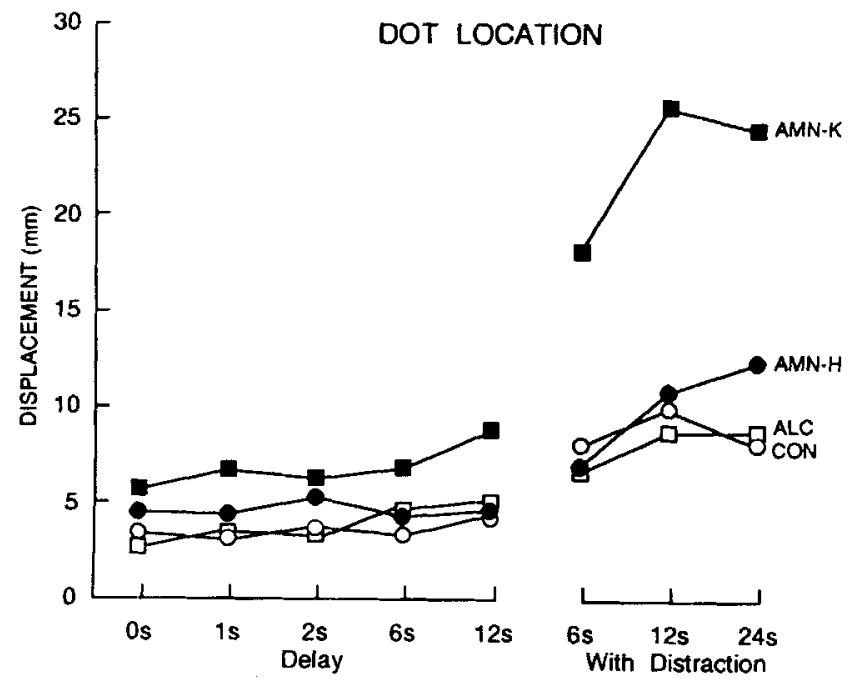

Fig. 4. Memory for dot location. The displacement score is a measure of error. The left panel shows performance with unfilled delays. The right panel shows performance with distraction-filled delays. CON, healthy control subjects; AMN$\mathrm{H}$, patients with damage to the hippocampal formation; ALC, alcoholic control subjects; AMN-K, patients with Korsakoff's syndrome.

\section{Patients with Korsakoff's syndrome}

On trials with unfilled delays, the patients with Korsakoff's syndrome performed more poorly than the alcoholic control subjects (Fig. 4). The average error in placement was $3.7 \mathrm{~mm}$ for the alcoholic control subjects and $6.9 \mathrm{~mm}$ for the patients $(F[1,10]=10.5, P<.01)$. Performance declined at longer delays $(F[4,40]=6.0, P<.001)$. The patients also performed more poorly than the control subjects on the distraction-filled delays (alcoholic controls, mean error, $8.0 \mathrm{~mm}$; patients, mean error, $22.6 \mathrm{~mm} ; F[1,10]=28.6, P<.001)$. There was a trend toward poorer performance at the longer delays ( $P$ $<.10)$.

The two patient groups performed similarly on trials with unfilled delays $(P>.10)$. Performance was marginally poorer as the delay increased $(F[4,36]=2.3, P<.08)$. The patients with Korsakoff's syndrome tended to make larger errors in placement with longer delays $(F[4,36]=3.0, P<.05$, for the interaction between delay and subject group). On trials with filled delays, the patients with Korsakoff's syndrome performed more poorly than the patients with damage to the hippocampal formation $(F[1,9]=15.9, P<.01)$. Performance tended to be poorer at longer delays $(F[2,18]=3.5$, $P<.06$ ), and there was no patient group by delay interaction.

\section{Discussion}

Patients with damage to the hippocampal formation performed normally at short delays in this task of spatial mernory. At the longest delay, performance tended to be impaired $(t[15]=2.0, P<.07)$. Presumably, this task should be dependent on allocentric spatial representation, because both the dot and the line move during the delay and subjects must therefore remember the location of the dot relative to the line. An egocentric representation (i.e., remembering the location of the dot relative to oneself) would prove quite ineffective. Accordingly, the finding that the patients performed normally at the short delays suggests that the hippocampal formation is not performing a function critical for the computation or short-term retention of allocentric location information. In an earlier study, amnesic patients were normal at a similar task involving remembering the location of a single dot on a sheet of paper after a 60-second delay (Warrington and Baddeley, 1974). However, that task was not so clearly an allocentric spatial task in that the stimulus location did not move during the delay. Therefore, it might have been possible to remember the location of the dot in relation to oneself or in relation to other surroundings. Finally, the amnesic patient H.M. was severely impaired on a similar task (cited in Smith, 1988). As discussed elsewhere (Squire and Zola-Morgan, 1991; Squire, 1992), H.M. is more severely amnesic than the study patients tested here and also has more extensive damage to the medial temporal lobe than these patients.

The patients with Korsakoff's syndrome had significant difficulty with the task, performing more poorly than their control subjects at all delays (even 0 seconds, $t[10]=3.6, P<$ $.01)$. These results provide support for the idea that these patients have deficits in addition to impaired memory. The patient's with Korsakoff's syndrome were also more sensitive to distraction than patients with damage to the hippocampal formation. This deficit may be due to frontal lobe damage 
(e.g., to difficulty in deploying attentional resources). In support of this suggestion, two memory-impaired patients with diencephalic lesions (N.A. and M.G.) performed considerably better than the patients with Korsakoff's syndrome. Their performance across delays was similar to the performance of patients with hippocampal damage (average displacement scores on trials with 6,12 , and 24 seconds of distraction, $5.6,11.3$, and $11.2 \mathrm{~mm}$, respectively).

\section{EXPERIMENT 4}

Experiment 4 evaluated the ability to remember and judge a simple perceptual relationship within the span of immediate memory. The task required that subjects remember the orientations of two lines that intersected at one end, and to judge whether two lines presented subsequently were or were not oriented at the same angle as the first two lines.

\section{Methods}

\section{Subjects}

The same patients and control subjects tested in experiment 3 were tested in experiment 4 .

\section{Materials}

The test required subjects to study an angle on a computer screen (Fig. 1), and then to determine after a delay $(0.5,1$, 2,6 , or 12 seconds) whether a second angle was the same as or different from the original angle. Eighty different angles were used. For study, the angles were displayed in black on a white background. Twenty of the angles were oriented so that they opened to the left, 20 opened to the right, 20 opened in the upward direction, and 20 opened in the downward direction. Half were acute angles and half were obtuse. At test half the stimuli were the same as what was displayed at study, and half were different angles from the ones shown at study. Of the "different" stimuli, half were $19^{\circ}$ smaller and half were $19^{\circ}$ larger than their corresponding study angle. The study and test angles were centered at the same place on the computer screen.

Trials were arranged such that equal numbers of "same" and "different" trials at each delay interval occurred within each group of 20 trials ( 80 trials total). The five kinds of delay trials $(0.5,1,2,6$, or 12 seconds) were presented in random order, with the constraint that no more than three trials of the same delay or requiring the same response occurred consecutively. Five different tests were prepared such that each stimulus could be tested at each of the five delays. Each subject took one of the tests, and each group of five subjects took all five tests.

\section{Procedure}

The subjects were asked to study an angle and then, after a delay, to decide whether a second angle was exactly the same as or different from the first. Verbal instructions were accompanied by index cards illustrating what would occur on the computer screen. Subjects were told that the difference between a study and test angle, when it occurred, would be subtle, and an example was provided to illustrate the difference. The test then began with six practice trials given with feedback. Subjects pressed the spacebar on the computer keyboard to initiate each trial. An angle was presented on the computer screen (black on white) for 1 second. The screen was then a uniform gray during the delay $(0.5,1,2,6$, or 12 seconds). (A delay of 0 seconds was not used in order to avoid apparent motion in the "different" trials.) Following the delay, a second angle appeared and remained on the screen until the subject responded. The subject was to decide as accurately as possible whether or not the second angle was exactly the same as the first one. The " $z$ " and "/" keys on the computer keyboard were used to make responses, with the key designated "same" counterbalanced between subjects and within hand preference. Labels with the designations "same" and "diff"' were affixed to the response keys. No feedback was provided during the test trials.

\section{Scoring}

The error rate (misses plus false alarms divided by the total number of trials) was determined for each subject at each delay.

\section{Results}

\section{Patients with damage to the hippocampal formation}

The patients and the control subjects performed similarly (Fig. 5). The average error for the control subjects was $20.1 \%$ and for the patients was $20.6 \%(F<1)$. Performance declined at longer delays $(F[4,60]=19.4, P<.001)$.

\section{Patients with Korsakoff's syndrome}

The patients with Korsakoff's syndrome performed marginally more poorly than the alcoholic control subjects (Fig. 5 ). The average error for the alcoholic control subjects was $20.2 \%$, and the error for the patients was $29.8 \%(F[1,10]=$ $4.6, P<.06)$. Performance declined at longer delays $(F[4,40]$

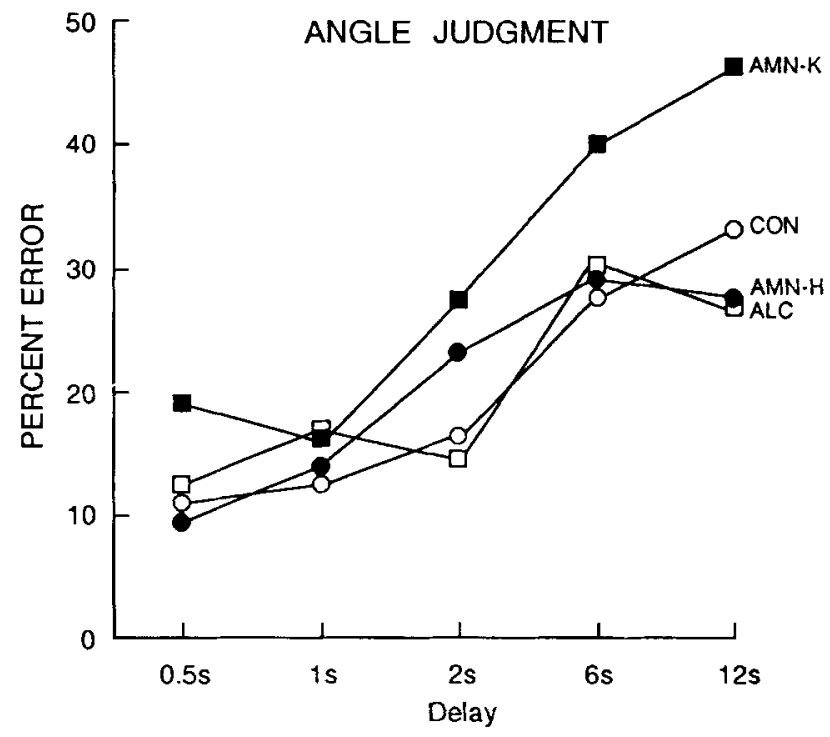

Fig. 5. Percent error for same/different judgments of angles. $\mathrm{CON}$, healthy control subjects; $\mathrm{AMN}-\mathrm{H}$, patients with damage to the hippocampal formation; ALC, alcoholic control subjects; AMN-K, patients with Korsakoff's syndrome. 
$=7.8, P<.001)$. There was no interaction between subject group and delay.

The patients with Korsakoff's syndrome performed marginally more poorly than the patients with damage to the hippocampal formation $(F[1,9]=5.1, P<.06)$.

\section{Discussion}

The patients with damage to the hippocampal formation performed normally. They demonstrated no difficulty in remembering the relative orientation of two lines across short delays. Patients with Korsakoff's syndrome performed this task more poorly than the alcoholic control group and more poorly than patients with damage to the hippocampal formation. Their difficulty does not seem attributable to diencephalic damage, as patients N.A. and M.G. performed within the normal range at all delays.

Experiments 1-4 demonstrated that patients with damage to the hippocampal formation have an intact ability to apprehend, encode, and retain relations among verbal or nonverbal stimuli within the span of immediate memory. Experiment 5 combined all of these elements and required in addition the mental manipulation of visual information within short-term memory.

\section{EXPERIMENT 5}

Experiment 5 evaluated the ability to perform mental manipulations of information within the span of immediate memory.

\section{Methods}

\section{Subjects}

The subjects were the same as those tested in experiments 3 and 4.

\section{Materials}

The task required subjects to study a $3 \times 3$ array of shaded and unshaded squares (Fig. 1) and then to decide whether or not a second array was a correct mirror reversal (in either the left-right or top-bottom direction) of the original array. There were two kinds of trials: those with no delay, and those with a 24-second, distraction-filled delay between study and test.

There were 40 "no-delay" trials and 16 trials with 24 -second, distraction-filled delays. The no-delay trials were administered on one day and the filled-delay trials were administered on a subsequent day. Left-right and up-down trials occurred equally often. In addition, each response (yes or no) occurred equally often in each quarter of the no-delay trials and within each half of the 24-second trials. The order of trials was random with the constraint that no more than three trials requiring the same direction of reversal or the same response occurred consecutively.

\section{Procedure}

The subjects studied a pattern on a Macintosh computer screen, mentally reversed the pattern in the direction indicated by an arrow, and then decided whether a second pattern was or was not a correct reversal of the original pattern. Ver- bal instructions were accompanied by index cards illustrating what would occur on the computer screen. Six practice trials with feedback were given to ensure that the instructions were clearly understood.

No-delay trials. The subjects pressed the computer keyboard spacebar to initiate a trial. Then a nine-square grid (approximately $4.5 \mathrm{~cm}$ square) appeared in the center of the computer screen. Four of the squares were always shaded and five were white. The pattern was displayed for 3 seconds. Following the study period, an arrow (two-ended, $4.3 \mathrm{~cm}$ long) appeared on the screen for 1 second. A horizontal arrow signaled that the original pattern should be mentally reversed in the leftright direction; a vertical arrow signaled a top-bottom reversal. Then a second nine-square grid with four shaded squares appeared and remained on the screen until the subject responded. The subject was to decide whether the second pattern was a correct reversal of the original pattern in the direction previously indicated by the arrow. Subjects made their response by pressing either the " $z$ " or " $/$ " key on the computer keyboard, with the key designated "yes" counterbalanced between subjects and within hand preference. The keys were labeled "yes" for correct reversal or "no" for incorrect reversal.

Trials with distraction-filled delays. These trials were identical to those just described except that a 24 -second, distractionfilled interval occurred between the arrow and the final pattern. The distraction task was the same as in experiment 3 .

\section{Results}

The error rate (misses plus false alarms divided by the total number of trials) was calculated for no-delay trials and delay trials.

\section{Patients with damage to the hippocampal formation}

The patients and the control subjects performed similarly (Fig. 6). Averaged across no-delay and delay trials, the error rate for the patients was $24.6 \%$, and the error rate for the

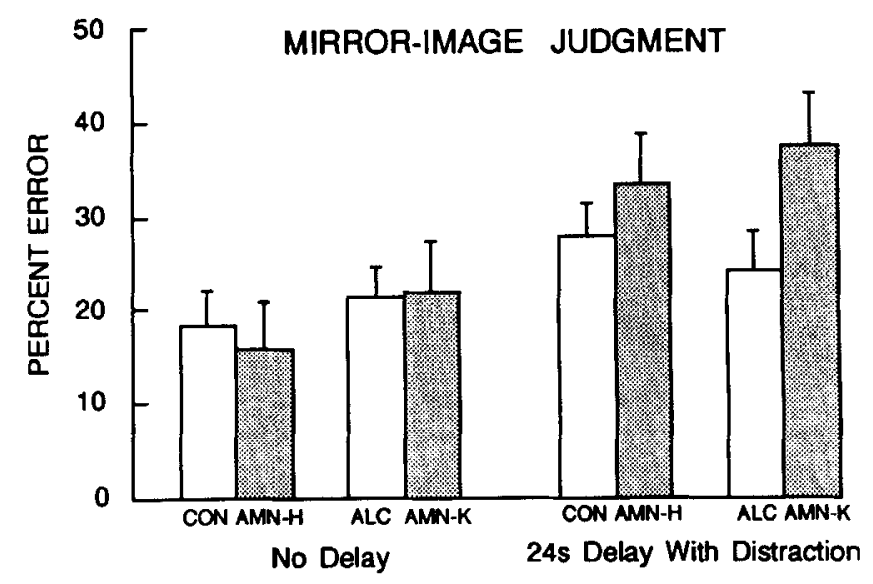

Fig. 6. Percent error for judging whether a test stimulus was a correct mirror reversal of the study stimulus. CON, healthy control subjects; AMN-H, patients with damage to the hippocampal formation; ALC, alcoholic control subjects; AMN$\mathrm{K}$, patients with Korsakoff's syndrome. 
healthy control subjects was $23.1 \%(F<1)$. Performance was poorer on the delay trials than on the no-delay trials $(F[1,15]$ $=13.3, P<.01$ ).

\section{Patients with Korsakoff's syndrome}

The patients and alcoholic control subjects also performed similarly (Fig. 6). The error rate for the patients was $29.7 \%$, and the error rate for the control group was $22.8 \%(P>.2)$. Performance was poorer on delay trials than on no-delay trials $(F[1,10]=7.6, P<.02)$, but the patients tended to make more errors than the control subjects at the 24-second delay $(F[1,10]=4.8, P<.06$, for the group by delay interaction).

The two groups of patients performed similarly on both task conditions $(F<1)$.

\section{Discussion}

Patients with damage to the hippocampal formation were entirely normal at the mental manipulation of complex patterns within immediate memory. With a 24 -second delay, performance was poorer for both patients and normal subjects. Although the patients performed numerically more poorly than normal subjects after the 24-second delay, this difference was not significant. It is also possible to view this task as involving the acquisition, manipulation, and retention of allocentric spatial information. Subjects appeared to learn the arrays as a pattern of squares, i.e., in terms of how they related to each other spatially. It is not clear how the position of each square could have been learned in relation to the subject's position in space, or how each arbitrary pattern could have been encoded as an integrated unit with respect to the subject's position.

The patients with Korsakoff's syndrome performed normally when there was no delay and poorly after a 24 -second delay. The poor performance of the patients with Korsakoff's syndrome on the long delay does not seem attributable to diencephalic damage, as the two patients with diencephalic damage performed the task quite well. Their error rates averaged $15 \%$ and $21.8 \%$ on the no-delay and 24 -second delay trials, respectively.

\section{GENERAL DISCUSSION}

A test of digit span memory and four different tests of nonverbal short-term memory were given to two groups of amnesic patients. One group of patients had confirmed or suspected damage to the hippocampal formation, and the other group had diencephalic amnesia resulting from alcoholic Korsakoff's syndrome. The standard digit span test was used to assess verbal short-term memory, and it was administered on seven different occasions in order to obtain a more precise measure of short-term memory performance in amnesia than has been available previously. The four tests of short-term memory assessed the ability to apprehend, retain, or manipulate nonverbal information-all within the span of immediate memory.

Amnesic patients with damage to the hippocampal formation were entirely normal on all the short-term memory tests. Their digit span was normal (mean 6.8 digits vs. mean 6.8 for control subjects). They also performed normally on four tests of nonverbal memory in which they estimated the number of dots that had been briefly presented, recalled the position of a dot on a line, retained the size of an angle in order to make a same/different judgment, and judged whether a design initially presented for 3 seconds was subsequently displayed as a correct mirror-image reversal. Subjects performed more poorly as the delay interval increased between stimulus presentation and the time when the judgment was made, indicating the expected relationship between memory performance and retention interval (experiments 3, 4, and 5). In experiment 3 , the patients tended to perform worse than their control subjects at a 24-second delay, consistent with the deficits in long-term memory that have been extensively documented in this patient group (cf. Tables 1 and 2).

The cognitive mapping hypothesis of hippocampal function proposed that the hippocampus constructs and stores spatialtemporal representations of the external world ( $O$ 'Keefe and Nadel, 1978). In recent experiments we found that long-term memory for spatial information (e.g., the locations of objects) was no more impaired by hippocampal damage than memory for other kinds of information (e.g., the names of the objects) (Cave and Squire, 1991). That is, spatial and nonspatial memory were equivalently impaired. The present experiments indicate that the hippocampus is not needed to carry out computations within immediate memory across a variety of different tasks, including one that tested short-term memory for spatial location (experiment 3 ). These two sets of findings are consistent with the idea that the hippocampus is performing a general function in support of long-term memory and that short-term memory, including short-term spatial memory, is independent of the hippocampus (Squire and Cave, 1991). Recent studies in animals are consistent with this conclusion (Eichenbaum et al., 1988; Sutherland and Rudy, 1989; Squire, 1992).

In marked contrast to the patients with hippocampal damage, the patients with Korsakoff's syndrome performed poorly on several of the short-term memory tasks. First, their verbal immediate memory capacity was marginally low, although the difference between their score and the score of their control group arose largely because of the unexpectedly good performance of their alcoholic control subjects. It is worth noting that patients with Korsakoff's syndrome have frontal lobe atrophy (Shimamura et al., 1988) and that frontal lobe damage can impair forward digit span (Janowsky et al., 1989).

The patients with Korsakoff's syndrome also had difficulty on three of the four nonverbal tests. They were impaired in estimating dot displays (experiment 2, Fig. 3), and they demonstrated poor dot location memory even at a zero-second delay (experiment 3, Fig. 4). Finally, they tended to perform more poorly than their control subjects in judging angles (experiment 4, Fig. 5). Previous studies have also documented deficits in early-stage perceptual processing in this patient group (Talland, 1965; Kapur and Butters, 1977; Dricker et al., 1978). In addition, elevated visual-recognition thresholds for words and visual patterns have been reported (Oscar-Berman et al., 1973). In addition to these difficulties, patients with Korsakoff's syndrome are abnormally distractable and subject to interference (Cermak et al. 1971; 1977; Kinsbourne and Wood, 1975). Consistent with these earlier findings, these patients performed especially poorly in experiments 3 and 5 
of the present study when distraction was introduced during delays.

We suggest that these deficits are due to the effects of frontal lobe damage rather than the memory impairment itself. This idea is supported by the finding that two amnesic patients (N.A. and M.G.), who have amnesia as a result of circumscribed diencephalic damage, performed normally on all of the short-term memory tasks and were not unusually distractable. Indeed, some of the cognitive deficits associated with Korsakoff's syndrome have been observed in patients with frontal lobe damage, who are not themselves amnesic (Moscovitch, 1982; Squire, 1982; Janowsky et al., 1989).

In summary, the present results strongly support the classical view that short-term (immediate) memory is intact in amnesia. In particular, damage to the human hippocampus had no detectable effect on any of five measures, including four tests that assessed the ability to apprehend, retain, or manipulate nonverbal information within the span of immediate memory. In addition, one of the latter tests assessed the ability to retain in short-term memory information about spatial location. Thus, we could find no evidence that the hippocampus is needed for computations within short-term memory, including computations involving allocentric space. Nevertheless, short-term memory, including spatial shortterm memory, can be tested in a number of ways, and one cannot rule out entirely the possibility that some kind of computation important to perceptual processing or short-term memory may yet prove to be dependent on the hippocampus. At the same time, it is remarkable that during four decades of neuropsychological research, beginning with patient H.M. (Scoville and Milner, 1957), such a result has not been obtained.

\section{ACKNOWLEDGMENTS}

Supported by the Medical Research Service of the Department of Veterans Affairs, NIMH Grant MH24600, The Office of Naval Research, the McKnight Foundation, and an NIMH postdoctoral fellowship to C. B. Cave (MH09913).

The authors thank Teresa Doksum, Kathleen Fuchs, and Joyce Zouzounis for research assistance.

\section{References}

Atkinson, R. C., and R. M. Shiffrin (1968) Human memory: A proposed system and its control processes. In The Psychology of Learning and Motivation: Advances in Research and Theory, $\mathrm{K}$. W. Spence and J. T. Spence, eds., pp. 89-195, Academic Press, New York.

Baddeley, A. D. (1981) The concept of working memory: A view of its current state and probable future development. Cognition 10:1723.

Baddeley, A. D., and E. K. Warrington (1970) Amnesia and the distinction between long- and short-term memory. J. Verb. Learning Verb. Behav. 9:176-189.

Butters, N., and L. S. Cermak (1980) Alcoholic Korsakoff's Syndrome: An Information Processing Approach to Amnesia. Academic Press, New York.

Butters, N., and D. T. Stuss (1990) Diencephalic amnesia. In Handbook of Neuropsychology, Vol. 3, F. Boller and J. Grafman, eds., pp. 107-148, Elsevier, Amsterdam.

Cave, C. B., and L. R. Squire (1991) Equivalent impairment of spatial and nonspatial memory following damage to the human hippocampus. Hippocampus 1:329-340.

Cermak, L. S., L. Reale, and D. DeLuca (1977) Korsakoff patients nonverbal vs verbal memory: Effects of interference and mediation on rate of information loss. Neuropsychologia 15:303-310.

Cermak, L. S., N. Butters, and H. Goodglass (1971) The extent of memory loss in Korsakoff patients. Neuropsychologia 9:307-315.

Damasio, A. R. (1984) The anatomic basis of memory disorders. Semin. Neurol. 4:223-225.

Drachman, D. A., and J. Arbit (1966) Memory and the hippocampal complex. Arch. Neurol. 15:52-61.

Dricker, J., N. Butters, G. Berman, I. Samuels, and S. Carey (1978) Recognition and encoding of faces by alcoholic Korsakoff and right hemisphere patients. Neuropsychologia 16:683-695.

Eichenbaum, H., A. Fagan, P. Mathews, and N. Cohen (1988) Hippocampal system dysfunction and odor discrimination learning in rats: Impairment or facilitation depending on representational demands. Behav. Neurosci. 102:231-339.

Gilbert, J., R. Levee, and K. Catalano (1968) A preliminary report on a new memory scale. Percept. Mot. Skills 27:277-278.

Ginsburg, N. (1978) Perceived numerosity, item arrangement, and expectancy. Am. J. Psychol. 91:267-273.

Glanzer, M., and A. R. Cunitz (1966) Two storage mechanisms in free recall. J. Verb. Learn. Verb. Behav. 5:351-360.

Haxby, J. V., S. L. Lundgren, and G. K. Morley (1983) Short-term retention of verbal, visual shape and visuospatial location information in normal and amnesic subjects. Neuropsychologia 21:2533.

Jacobson, R. R., and W. A. Lishman (1987) Selective memory loss and global intellectual deficits in alcoholic Korsakoff's syndrome. Psychol. Med. 17:649-655.

James, W. (1890) Principles of Psychology. Holt, New York.

Janowsky, J. S., A. P. Shimamura, M. Kritchevsky, and L. R. Squire (1989) Cognitive impairment following frontal lobe damage and its relevance to human amnesia. Behav. Neurosci. 103:548-560.

Kapur, N., and N. Butters (1977) An analysis of the visuoperceptual deficits in alcoholic Korsakoff and long-term alcoholics. J. Stud. Alcohol 38:2025-2035.

Kaufman, E. L., M. W. Lord, T. W. Reese, and J. Volkman (1949) The discrimination of visual number. Am. J. Psychol. 62:498-525.

Kinsbourne, M., and F. Wood (1975) Short-term memory processes and the amnesic syndrome. In Short-term Memory, D. Deutsch and J. A. Deutsch eds., pp. 258-291, Erlbaum, Hillsdale, NJ.

Markowitsch, H. J. (1988) Diencephalic amnesia: A reorientation towards tracts? Brain Res. Rev. 13:35, 1-370.

Mattis, S. (1976) Dementia rating scale. In Geriatric Psychiatry, L. Bellak and T. B. Karasu eds., pp. 77-121, Grune \& Stratton, New York.

Milner, B. (1966) Amnesia following operation on the temporal lobes. In Amnesia, C. W. M. Whitty and O. L. Zangwill, eds., pp. 109133, Butterworths, London.

Milner, B. (1974) Hemispheric specialization: Scope and limits. In The Neurosciences: Third Study Program, F. O. Schmitt and F. G. Worden, eds., pp. 75-89, MIT Press, Cambridge, MA.

Monsell, S. (1984) Components of working memory underlying verbal skills: A "distributed capacities" view. In Attention and Performance, Vol. 10, H. Bouma and D. Bouwhuis, eds., pp. 327-350, Lawrence Erlbaum, Hillsdale, NJ.

Moscovitch, M. (1982) Multiple dissociation of function in amnesia. In Human Memory and Amnesia, L. S. Cermak, ed., pp. 337-370, Lawrence Erlbaum, Hillsdale, NJ.

O'Keefe, J., and L. Nadel (1978) The Hippocampus as a Cognitive Map. Oxford University Press, London.

Oscar-Berman, M., H. Goodglass, and D. G. Cherlow (1973) Perceptual laterality and iconic recognition of visual materials by Kor- 
sakoff patients and normal adults. J. Comp. Physiol. Psychol. 82:316-321.

Osterrieth, P. A. (1944) Le test de copie d'une figure complexe [The test of copying a complex figure]. Arch. Psychol. 30:206-356.

Parkinson, J. K., E. A. Murray, and M. Mishkin (1988) A selective mnemonic role for the hippocampus in monkeys: Memory for the location of objects. J. Neurosci. 8:4159-4167.

Penfield, W., and B. Milner (1958) Memory deficit produced by bilateral lesions in the hippocampal zone. Arch. Neurol. Psychiatry 79:475-497.

Posner, M. I., and A. F. Konick (1966) Short-term retention of visual and kinesthetic information. Org. Behav. Hum. Perform. 1:71-86.

Rey, A. (1964) L'examen clinique psychologie. Presses Universitaires de France, Paris.

Samuels, I., N. Butters, H. Goodglass, and B. Brody (1971) A comparison of subcortical and cortical damage on short-term visual and auditory memory. Neuropsychologia 9:293-306.

Scoville, W. B., and B. Milner (1957) Loss of recent memory after bilateral hippocampal lesions. J. Neurol. Neurosurg. Psychiatry 20:11-21

Shimamura, A. P., T. L. Jernigan, and L. R. Squire (1988) Korsakoff's syndrome: Radiological (CT) findings and neuropsychological correlates. J. Neurosci. 8:4400 4410.

Sidman, M., L. T. Stoddard, and J. P. Mohr (1968) Some additional quantitative observations of immediate memory in a patient with bilateral hippocampal lesions. Neuropsychologia 6:245-254.

Smith, M. L. (1988) Recall of spatial location by the amnesic patient H.M. Brain Cognition 7:178-183.

Squire, L. R. (1982) Comparisons between forms of amnesia: Some deficits are unique to Korsakoff's syndrome. J. Exp. Psychol. [Learn. Mem. Cogn.] 8:560-571.

Squire, L. R. (1987) Memory and Brain. Oxford University Press, New York.
Squire, L. R. (1992) Memory and the hippocampus: A synthesis from findings with rats, monkeys, and humans. Psychol. Rev. in press.

Squire, L. R., and C. B. Cave (1991) The hippocampus, memory, and space. Hippocampus 1:269-271.

Squire, L. R., and A. P. Shimamura (1986) Characterizing amnesic patients for neurobehavioral study. Behav. Neurosci. 100:866-877.

Squire, L. R., D. G. Amaral, S. Zola-Morgan, M. Kritchevsky, and G. A. Press (1989) Description of brain injury in the amnesic patient N.A. based on magnetic resonance imaging. Exp. Neurol. 105:2325.

Squire, L. R., D. G. Amaral, and G. A. Press (1990) Magnetic resonance imaging of the hippocampal formation and mammillary nuclei distinguish medial temporal lobe and diencephalic amnesia. J. Neurosci. 10:3106-3117.

Squire, L. R., and S. Zola-Morgan (1991) The medial temporal lobe memory system. Science 253:1380-1386.

Sutherland, R. J., and J. W. Rudy (1989) Configural association theory: The role of the hippocampal formation in learning, memory, and amnesia. Psychobiol. 17:129-144.

Talland, G. A. (1965) Deranged Memory. Academic Press, New York.

Victor, M., R. D. Adams, and G. H. Collins (1989) The WernickeKorsakoff Syndrome and Related Neurological Disorders due to Alcoholism and Malnutrition, 2nd ed. F. A. Davis, Philadelphia.

Warrington, E. K. (1984) Recognition Memory Test. NFER-Nelson, Windsor.

Warrington, E. K., and A. D. Baddeley (1974) Amnesia and memory for visual location. Neuropsychologia 12:237-263.

Waugh, N. C., and D. A. Norman (1965) Primary memory. Psychol. Rev. 72:89-104.

Wickelgren, W. (1975) The long and the short of memory. In Shortterm Memory, D. Deutsch and J. A. Deutsch, eds., pp. 41-63, Academic Press, New York. 